\title{
Green Village Pertamina Integrated Terminal Surabaya: Strategy of Corpo- rate Social Responsibility (CSR) Towards the Sustainable development Goals (SDGs)
}

\author{
Aulia Ulfah Farahdiba ${ }^{*}$, Anis Yuzrin Qonita², Eddy Kurniawan² \\ ${ }^{1}$ Department of Environmental Engineering, Universitas Pembangunan Nasional “Veteran” Surabaya, East \\ Java, Indonesia \\ ${ }^{2}$ Pertamina Integrated Terminal Surabaya, Perak Bar. No. 277. Perak Utara Surabaya 60165, East Java, \\ Indonesian
}

*Corresponding author:

E-mail:

auliaulfah.tl@upnjatim.ac.id

\begin{abstract}
This study developed Corporate Social Responsible (CSR) to enhance the Sustainable Development Goals (SDGs) with the Pertamina Integrated Terminal Surabaya program. The company needs to strengthen its engagement with nearby villagers, and alignment between CSR efforts and community needs. Influenced Suitable program must have been considering based on condition, community potential, and capability from each district. District Perak Utara and District Jagir Surabaya have become the green village at Surabaya. Data collection within the previous conditions and the program developed has been analyzed. Research recommends active engagement within the community in decision making at all stages of community development in each program that gives exclusive powers to traditional leaders or cadre.
\end{abstract}

Keywords: Green village, community development, Corporate Social Responsible (CSR), Sustainable Development Goals (SDGs)

\section{Introduction}

United nations publish a goal agreed by almost all countries, called SDGs (Sustainable Development Goals). SDGs have 17 objectives with six principles of activities to reduce environmental damage, like clean water and sanitation, climate change, affordable and clean energy, sustainable cities and communities, life below water, life on land (UNDP, 2017). Industrial activity will include in this commitment by producing innovative products. In Indonesia, as many as 94 targets of SDGs are incorporated in the MediumTerm Planning Document (RPJMN) of 2014-2019. Furthermore, SDGs are even more mainstreamed into the RPJMN of 2020-2024, where 105 out of 118 targets that are relevant to Indonesia have been incorporated into the RPJMN of 2020-2024 (SDGs Team/Ministry of National Development Planning, 2018).

Furthermore, companies must concentrate on the stakeholders involved in obtaining maximum objectives. The intended stakeholders are government institutions, private institutions, educational institutions, consumers, and the public. Without the role and support of other stakeholders, the company will not be able to achieve the stated goals. In order to maintain the relationship between the company and stakeholders, the Pertamina Integrated Terminal Surabaya has the initiative and commitment to participate in community development to accelerating the achievement of SDGs agreed in the government program. The application of social responsibility is also one of the targets of the SDGs. Pertamina Integrated Terminal Surabaya becomes an essential role in reducing environmental degradation. This study will discuss one of the oil and gas industries in Indonesia, Integrated Terminal Surabaya initiated the integrated CSR movement. Therefore, this

How to cite:

Farahdiba, A. U., Qonita, A. Y., \& Kurniawan, E. (2020). Green village pertamina integrated terminal Surabaya: Strategy of Corporate Social Responsibility (CSR) towards the sustainable development goals (SDGs). 1st International $^{\text {s. }}$ Conference Eco-Innovation in Science, Engineering, and Technology. NST Proceedings. pages 41-46. doi:10.11594/ nstp.2020.0505 
study expects to be a benchmark or integrated study case that can be carried out by similar industries in Indonesia.

\section{Definition Corporate Social Responsibility (CSR) in the business sector towards to SDGs}

Corporate Social Responsibility is the commitment of the business in ethical behavior by participating in improving the economy, the quality of employees, families, and local communities. CSR activities are the company's ability to respond to the surrounding social environment. The concept of caring for stakeholders is often referred to as corporate social responsibility (CSR) (Xia, Olanipekun, Chen, Xie, \& Liu, 2018). The concept was held by the Indonesian government in cooperation with all companies to participate in social responsibility, regulated in Law No.40 of 2007. Social and Environmental Responsibility is the company's commitment to participate in sustainable economic development in order to improve the quality of life and the environment that is beneficial, both for the company itself, the local community, and society in general (Law No.40 of 2007 Incorporated company, 2007).

There are four categories of forms of CSR. First, proper environmental management to create a safe and comfortable environment and not interfere with the survival of employees and the surrounding community. Second, cooperation between companies and the community to realize community development programs to improve community sustainably welfare. The purpose of this program is that the community can receive company benefits as a supporter of a creative and independent community. Third, the environmental sustainability of the company, which includes saving electricity, water, and waste management impacts from existing production processes. Fourth, social investment. The form of company actions in providing financial and non-financial support in social and environmental activities (Nurunnabi et al., 2019). CSR is very relevant to achieving the sustainable development goals (SDGs). Of note, the SDGs are the recent efforts of the United Nations (UN) to strengthen global peace and eradicate poverty in all its forms and dimensions towards achieving sustainable development for the people, planet, and prosperity (Xia et al., 2018).

\section{Material and Methods}

Pertamina Integrated Terminal Surabaya is an industry engaged in the distribution of oil and gas. The capacity with 25 tanks or 139,059 Kiloliters of oil and gas with an area of $14 \mathrm{Ha}$. Pertamina Integrated Terminal Surabaya has a diverse distribution system, using pipeline, fuel rucks with New Gantry System (NGS), and tankers. The strategy used to obtain the company's goals is by implementing a culture of innovation.

\section{Definition strategy of CSR pertamina integrated terminal Surabaya CSR program in pertamina integrated terminal Surabaya}

Pertamina Integrated Terminal Surabaya has two green village concept areas with different locations, District Perak Utara (Hamlet 08 and 09) and District Jagir Surabaya (Hamlet 04) which is located nearby to the company. Pertamina Integrated Terminal Surabaya considered the concept of CSR includes:

1. Environment consideration

Pertamina Integrated Terminal Surabaya proposes that the environment is the main aspect of implementing CSR. This aspect is prioritized because of the company background that managed to obtain a green proper in 2012, 2014, 2015, 2016, and received an environment award through PROPER from the Ministry of Environment and Forestry of Indonesia in 2018. In addition, environmental aspects are emphasized to foster self-awareness, provide knowledge and environmental management.

\section{Economic strengthening}

Pledge of Pertamina Integrated Terminal Surabaya is community empowerment within economic strengthening. The community is empowered to produce products that have high sales 
value in order to earn income and eradicate unemployment (İyigün, 2015). This is conduct to form an independent community (Wilson, 2015).

3. Community-based management

The management aspect needs to be developed in the community to arrange strategies in managing the results of community products. The management aims to develop the business and make the mainstay products favored by consumers so that the business carried out by the community can be sustainable (Acharya \& Patnaik, 2018).

4. Social Empowerment

The implementation program of Pertamina Integrated Terminal Surabaya forms the community and environmental potential of each region. The community is expected to be creative, independent, and aware of environmental concerns (Tang-Lee, 2016).

\section{Evaluation of existing condition}

Pertamina Integrated Terminal Surabaya approaches youth, community and helmets units. Before implementing community empowerment, it is necessary to recognize the potential and environmental conditions so that the programs that have been prepared are right on target (Liao et al., 2017).

Several factors need to be improved from the evaluation of existing conditions. In order with the social perspective, the community is quite apathetic about their surroundings. Many communities in the neighborhoods who experience economic inequality. Moreover, many migrants have low environmental awareness. There are some environmental conditions; slums, arid conditions, and poor waste management. Odors and maggots would emerge if waste was not appropriately managed. It causes the community to prefer to do activities inside the house rather than socializing outside the house. These environmental conditions will adversely affect the survival of the community.

Pertamina Integrated Terminal Surabaya found the community potential that can be developed. Mothers and teenagers have a high interest involved in the program. There is a marketing network and access to institutions and the existence of social capital supported by the city government. This potential could extended to improve the existing problems in the village. The difference in the problematic situation, Jagir district is that there is a narrow area of land and many older people.

The problems and potentials of each district create different strategic planning. The program to be implemented later is expected to develop sustainably because of community support. In this case, the community is involved as a leader. Furthermore, the program planning to be implemented must be following the needs, interests, desires of the community, and potential environmental conditions (Lu et al., 2019)

\section{Implementation program of pertamina integrated terminal Surabaya}

1. Wastewater treatment

Pertamina Integrated Terminal Surabaya has made programs in accordance with the conditions and potential of each village. The program that has created is expected to make the community creative, independent, and sustainable. Pertamina Integrated Terminal Surabaya decides the initiative to participate in public awareness and improving the environment.

The programs made begin with socializing about environmental awareness to changing community mindset. The socialization is not only limited to protecting the environment but also processing the waste, such as composting. Pertamina Integrated Terminal Surabaya also contributes to environmental management facilities or infrastructure, such as the construction of an integrated Wastewater Management Installation (IPAL) to treat the domestic wastewater (Figure 1). Integrated WWTP Development also applied in District Jagir. Waste water from WWTP can be used by the community to water plants. 


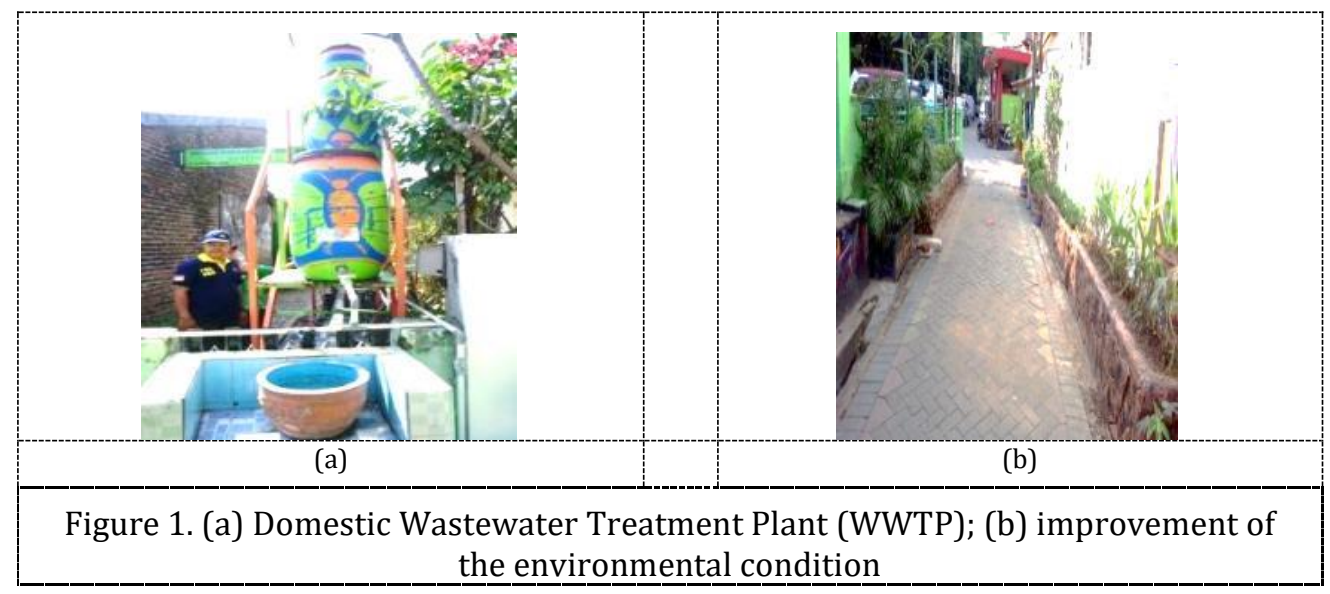

2. Small and medium enterprises (UKM) development

Small and Medium Enterprises (UKM) Cantiq (beautiful) (Figure 2) was formed to develop the economy community. UKM can be a solution to reduce the unemployment rate and overcome economic disparities. UKM can also train to be creative and independent communities (Osagie et al., 2016). In the development of Cantiq UKM, there are training in making cakes, recycling, screen printing, and embroidery. Mothers and teenagers have high motivation to learn the training, it has the potential to become a business in a sustainable economy. UKM also equipped with knowledge management to manage and develop business. The management outlines include marketing strategies and product development innovations. Environment-based programs that are appropriate to be implemented in the district are to form a Waste Bank. The purpose of establishing a Waste Bank is to raise public awareness of waste, minimize waste accumulation in Temporary Shelter (TPS), and Final Processing Sites (TPA). It could be utilized and manage waste into higher value. Pertamina Integrated Terminal Surabaya is expanding a community economic center in which there are: catfish and mushroom cultivation, handicraft, crackers. Youth and the elderly become the pioneer the promoting the program. Another CSR programs are training the community to make hydroponic plants and build hydroponic zones. Hydroponics is a method of farming other than planting media other than soil and water medium that could be used in a narrow area. The program is appropriately implemented in Jagir district because the district has limited area. The results of the hydroponics can be used by the public to become juice or gelatin (Figure 2).

3. Implementation of the healthy elderly program

Pertamina Integrated Terminal Surabaya proposes implementing the Healthy Elderly program in Jagir district. The program aims to support the health of the elderly by providing health counseling by doctors, conducting routine medical check-ups, providing vitamins, nutritious foods, and healthy exercise activities for the elderly (Figure 3).

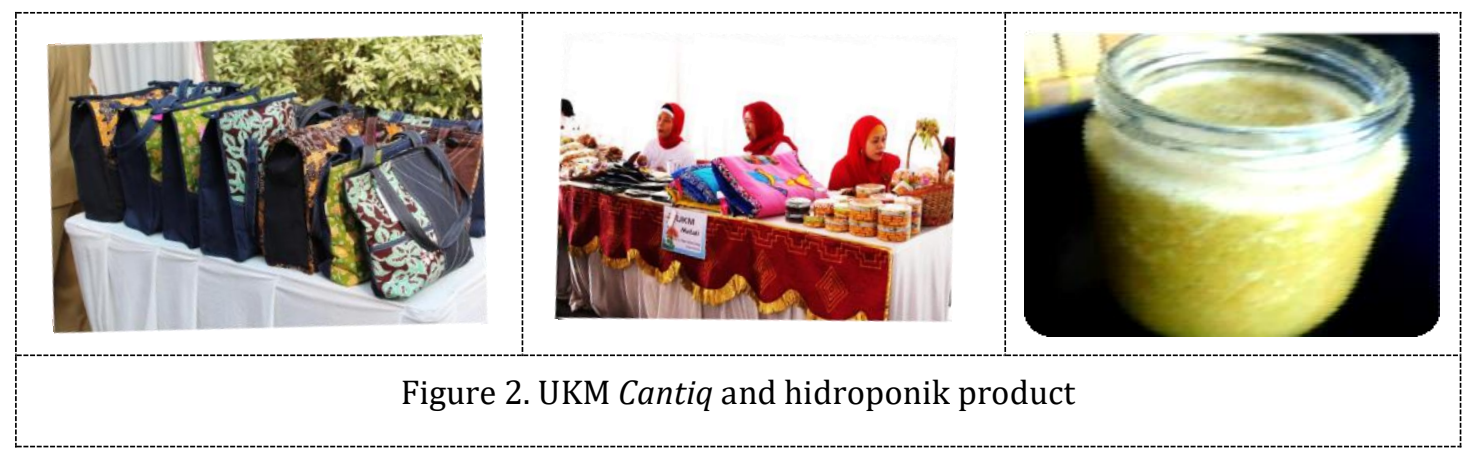




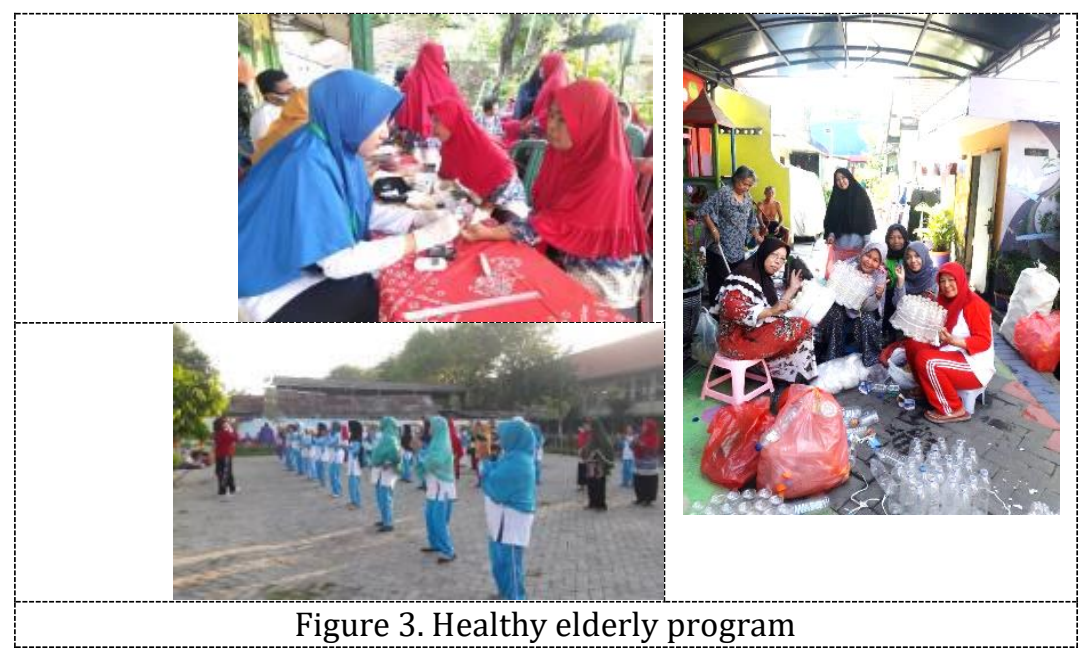

4. Health Safety Security \& Environment (HSSE) program

The program that has just been implemented is the HSSE (Health Safety Security \& Environment) program. The program aims to train the community in preparedness and response to a disaster such as a fire. The background of the emergence of this program initiative is the occurrence of a fire on Surabaya in 2017, which is close to the Jagir District. At that time, eight fire trucks had difficulty reach the location because the access road to the district was less than one meter and far from the water source. Therefore, there is a need for preparedness training to deal with and cope with similar incidents. This program is collaborative with the Surabaya City Fire Department (PMK) and referral hospital. The community is trained in how to identify the surrounding hazards, the evacuation process, and first aid that can be done. In addition, Pertamina Integrated Terminal Surabaya also supports by providing facilities and infrastructure such as emergency lights, fire alarms, first aid equipment, and handy talky.

\section{Results and Discussion}

After the programs that have been designed are realized. Each District has a privilege program that can significantly effect by the community (Rangan, Chase, \& Karim, 2015). District Perak Utara have excellent programs with UKM Cantiq, integrated WWTP, and solid waste management. KM Cantiq could develop with the potential cadre from the community, called Ms Joyce. She is local people who are willing to consistently promote and pursue Cantiq UKM Cantiq. UKM Cantiq has been running for six years with regular industrial and private customers. The product has sold and spread to Sulawesi. Income increases significantly every year. The highest achievement of income during operation, which reached Rp. 80,500,000 ( 5,144.18 USD/year) in 2017. 20\% of the income of the sales will be income for 35 managers of UKM Cantiq.

Business compost also has benefits to the community of Perak Utara District. The processed organic waste reaches $3,425 \mathrm{~m}^{3}$ every month. This makes 17 residents have the ability to manage waste and change the mindset of 14 helmets to maintain environmental health. Green village in Perak Utara district has a hydroponic program, waste bank, Integrated WWTP, Community Economic Center, and Healthy Elderly Program. In its realization, the local community certainly participated in the various programs. Mr. Suyono is a local community of the Green Village Environment. Many benefits can be significantly affected to the community (İyigün, 2015). Water utilization from the WWTP management of reaches 182,500 liters/year. The results of the processed water can save the use of water for watering plants as much as Rp 63,875,000/year $(4,081$ USD/year). This program could be a benchmark for other urban communities. Mojokerto community group who visited the Green Village Pertamina and has succeeded in replicating the WWTP in the area where he lives. Hydroponic program could be covering an area of 15 hectares into a 
productive area and can save up to Rp 17,348,000/ year ( 1,114 USD/year). The programs that have been developed by Pertamina Integrated Terminal Surabaya won an innovative Kampung award from the Mayor of Surabaya in 2015 and made it into the top 50 Green and Clean competitions at Surabaya.

\section{Conclusion}

Implementation of CSR requires depth analysis between the potential condition in each district. Pertamina Integrated Terminal Surabaya with the green village concept is subject to social responsibility requirements for environment, social, and economic impacts with enhancing SDGs commitment. CSR program is an effective means to present the society their effort by communitybased management. The present study contributed to filling this gap and helping corporations meet social demand by developing green village with local wisdom in each district.

\section{Acknowledgment}

We are grateful for this funding and support of this research.

\section{References}

Acharya, J., \& Patnaik, S. N. (2018). Corporate social responsibility in community development and sustainability: Rourkela Steel Plant, a unit of SAIL, India. Asian Journal of Business Ethics, 7(1), 53-79. https://doi.org/10.1007/s13520-017-0079-5

İyigün, N. Ö. (2015). What could Entrepreneurship do for Sustainable Development? A Corporate Social Responsibility-Based Approach. Procedia - Social and Behavioral Sciences, 195, 1226-1231. https://doi.org/10.1016/j.sbspro.2015.06.253

Law No.40 of 2007 Incorporated company. (2007).

Liao, P. C., Xia, N. N., Wu, C. L., Zhang, X. L., \& Yeh, J. L. (2017). Communicating the corporate social responsibility (CSR) of international contractors: Content analysis of CSR reporting. Journal of Cleaner Production, 156, 327-336. https://doi.org/10.1016/j.jclepro.2017.04.027

Lu, J., Ren, L., Lin, W., He, Y., \& Streimikis, J. (2019). Policies to promote corporate social responsibility (CSR) and assessment of CSR impacts. E a M: Ekonomie a Management, 22(1), 82-98. https://doi.org/10.15240/tul/001/2019-1-006

Nurunnabi, M., Esquer, J., Munguia, N., Zepeda, D., Perez, R., \& Velazquez, L. (2019). Reaching the sustainable development goals 2030: energy efficiency as an approach to corporate social responsibility (CSR). GeoJournal, 0123456789. https://doi.org/10.1007/s10708-018-09965-x

Osagie, E. R., Wesselink, R., Blok, V., Lans, T., \& Mulder, M. (2016). Individual Competencies for Corporate Social Responsibility: A Literature and Practice Perspective. Journal of Business Ethics, 135(2), 233-252. https://doi.org/10.1007/s10551-014-2469-0

Rangan, K., Chase, L., \& Karim, S. (2015). The truth about CSR. Harvard Business Review, (January-February 2015), 1-9.

SDGs Team/Ministry of National Development Planning. (2018). Roadmap of SDGs Indonesia Towards 2030. 162. Retrieved from http://sdgsindonesia.or.id/\%0Ahttps://drive.google.com/file/d/1SnQY_t52KZaEVub8U6JEh1rSL_BhrY3b/view

Tang-Lee, D. (2016). Corporate social responsibility (CSR) and public engagement for a Chinese state-backed mining project in Myanmar - Challenges and prospects. Resources Policy, 47, 28-37. https://doi.org/10.1016/j.resourpol.2015.11.003

UNDP. (2017). Challenges and Opportunities in the Implementation of the Rio+20 Ocean Outcome.

Wilson, S. A. (2015). Corporate social responsibility and power relations: Impediments to community development in post-war Sierra Leone diamond and rutile mining areas. Extractive Industries and Society, 2(4), 704-713. https://doi.org/10.1016/j.exis.2015.09.002

Xia, B., Olanipekun, A., Chen, Q., Xie, L., \& Liu, Y. (2018). Conceptualising the state of the art of corporate social responsibility (CSR) in the construction industry and its nexus to sustainable development. Journal of Cleaner Production, 195, 340-353. https://doi.org/10.1016/j.jclepro.2018.05.157 